\title{
Comparative Study between Various Reagents of Plastination in Making Museum Specimen
}

\section{Darshana Tote ${ }^{1}$, Sachin Tote ${ }^{2}$}

Section: Healthcare

Sci. Journal Impact

Factor: $6.1(2018)$

ICV: 90.90 (2018)

(c) (7) (3)

Copyright@IJCRR Maharashtra, India.
'Professor, Department of Surgery, ]awaharlal Nehru Medical College, Datta Meghe lnstitute of Medical Sciences, Wardha, Maharashtra, India; ${ }^{2}$ Assistant Professor, Department of Anatomy, ]awaharlal Nehru Medical College, Datta Meghe lnstitute of Medical Sciences, Wardha,

\section{ABSTRACT}

Background: Plastination uses polymer as an agent which preserves the specimen in a near-natural state. This technique has advantages over the traditional method of body part preservation and handling of the specimen. But the main drawback remains its cost and availability of the reagents. Till date, this technique of specimen preservation has not been used by any surgeon. Hence we plan to use this technique of plastination for the preservation of museum specimen. We also plan to compare various reagents used for the same as commercially available resins and touchwood primer paint.

Objectives: Primary objective: to study the efficiency of various reagents of plastination for the preservation of the surgical specimen.

Methods: This is a prospective interventional randomized study over 1 year period. Study population: 5 specimens in each group of reagent. All the specimens in both groups will be subjected to the same process of Plastination, specimen selection, dehydration and defatting, vacuum impregnation, positioning, curing, specimen analysis over 6 months.

Results: The Plastination specimen of Touchwood reagent will be compared with the standard Plastination reagent specimen in terms of durability, handling, clarity of specimen and cost-effectivity.

Conclusions: The specimen should be comparable to the specimen of epoxy resin reagent in terms of durability, clarity and ease of handling.

Key Words: Plastination, Surgery museum specimen, Resin, Touchwood paint

\section{INTRODUCTION}

The concept of visualizing any specimen or body part virtually and in real-world has got different impacts on medical students. Anatomist uses human bodies as an educational tool to teach medical graduates ${ }^{1}$ while the diseased organs are taught in surgery with the help of mounted specimens. Various studies have proven that human bodies have some definitive characteristics and hence there is no alternative to it as an educational tool. Recently there has been a lot of discussion amongst the anatomists against the utility of dissection as a useful method. ${ }^{2}$ Dissection is seen as an old fashioned way of virtualization. On the other side, some clinicians prefer using dissection as a tool to enhance the knowledge about human anatomy in a better way, but they feel that there is need for re-enhancing anatomical education by dissection.
The proper and efficient demonstration of the human organ is it normal or diseased needs a properly preserved and mounted specimen. Preservation is said to be proper when the body remains unharmed and free from decomposition. While dealing with this issue of body or body part preservation some definitions have to be clear. Merriam-Webster's dictionary $^{3}$ defines

Preservation: an action to keep something 'safe from harm, destruction or decomposition

Conservation: the process of 'a careful preservation and protection of something'

Embalmment: the 'treatment (of a dead body) - with special chemicals -to protect from decay. ${ }^{4}$

There are many solutions in use for the technique of embalming available with formaldehyde as the most common

\section{Corresponding Author:}

Dr. Darshana Tote, Shree Hospital, Bachelor Road, Radha Nagar, Wardha, Maharashtra-442001, India. Contact: 9923129974; Email: drtotedarshana@gmail.com

ISSN: 2231-2196 (Print)

Received: 18.09 .2020
ISSN: $0975-5241$ (Online)

Revised: 22.10 .2020
Accepted: 12.11 .2020
Published: 30.11 .2020 
in use. The use of methanol or formaldehyde is not considered as the user as well as environmentally friendly. The most dreadful disadvantage of the use of formaldehyde is its strong smell and generated irritant fumes. These drawbacks of formaldehyde arouse the need for a newer technique of specimen preservation i.e. Plastination which uses polymer as the agent. It helps to preserve the specimen in a near-natural state. In this technique, the lipids and the water present in the specimen are replaced with synthetic components like polyester or silicon. When this material is dried up a naturallooking and long-standing specimen is ready. ${ }^{5}$ The important advantage of this technique over traditional technique is that the anatomical details and handling of bodies or specimen is easy. ${ }^{6,7}$

Pioneer of Plastination as Gunther Von Hagens. He introduced this technique of Plastination in 1977 in the Department of Anatomy at the University of Heidelberg with patent received between 1978 and 1982. The most commonly used agents are

- Silicon polymer (S10) for the preservation of a realistic whole body or parts of organs

- Epoxy polymer (E12) for transparent body or tissue slicing

- $\quad$ Polyester polymer (P40) for encephalic sections ${ }^{8}$

The main drawback is the cost of all the available reagents. Hence there is a need to introduce a cost-effective reagent to replace these available reagents. With this aim, the topic is taken to evaluate the efficacy of an easily available and costeffective reagent for Plastination of specimen.

All the available reagents of Plastination are too costly and not readily available for Indian researchers easily. Hence there is a need to evaluate various readily available reagents with almost similar composition as a replacement to these costly reagents.

\section{MATERIALS AND METHODS}

Study Design: a prospective interventional randomized study

Setting: Specimen extracted from the surgeries conducted at AVBRH, Sawangi (Meghe), Wardha

Participants: 5 surgical specimens in each group of reagent

\section{Specimen selection:}

The specimen will be cleaned under tap water to get rid of formalin and cross section will be taken without disturbing the anatomical details. The arteries and vein can be injected with red and blue latex respectively., ${ }^{9,10}$

\section{Dehydration and defatting:}

The selected specimen will be kept completely immersed in acetone for dehydration in $\mathrm{a}-24^{\circ}{ }_{\mathrm{C}} 90-100 \%$ acetone bath to remove the water in an airtight container. The acetone bath will be repeated till the acetone purity will be reached $95 \%$ equilibrium. By his process, we will get the water free specimen.

Then the specimen will be kept in 99 to $100 \%$ acetone bath at room temperature for defatting as fats do not undergo proper Plastination. These 99 to $100 \%$ acetone bath will be repeated until the acetone purity will be above $98 \%$ equilibrium where we will have clear acetone and fat-free specimen. The process of dehydration will vary from specimen to specimen depending their permeability, thickness and amount of water and fat content. ${ }^{11}$

\section{Forced impregnation of Epoxy}

This is the crucial step of Plastination where epoxy polymer will replace the acetone from tissue spaces initially occupied by the water and fats. The extraction of acetone and filling of tissue by epoxy will be simultaneously accomplished by the vacuum. This will be carried out by placing the specimen in a container filled with epoxy, placed in a vacuum chamber. This process will last for a few weeks depending upon the type of tissue used. ${ }^{12}$

\section{Positioning}

The impregnated tissue will be properly aligned to maintain the anatomical structural detail of various tissue parts. During above all various process, delicate tissue part may change their placement.

\section{Curing}

This process will involve the application of the curing agent which catalyzes the reaction between the epoxy and its crosslinker resulting in hardening of the specimen. The catalyst used in the process will be Xylene. This will be aided by flowing air. ${ }^{13}$

Qualitative variables: all these specimens will be evaluated for
a. Durability
b. Ease of handling
c. Clarity of specimen
d. Cost effectivity

\section{EXPECTED OUTCOMES/ RESULTS}

Touchwood reagent of Plastination is efficiently comparable to the epoxy resin reagent of Plastination for the preservation of various surgical specimen for a longer duration. Low-cost 
reagents of Plastination can also be a good replacement for high-cost Epoxy Resins as Plastination Reagent. The plastinated specimen in both groups must be comparable because of
a. Durability
b. Ease of handling
c. Clarity of specimen
d. Cost effectivity

\section{DISCUSSION}

The method of plastination is new to our researchers hence there is a wide range of things that can be done in this field. Moreover need of the time is to have a good, durable, easily available and cost-efficient reagent for this process. Hence this study to evaluate the efficacy of newly introduced and readily available reagent as compared to the costly but in vogue Reagent.The study should be followed for a longer duration to assess the durability and usefulness of these specimens in long run.

\section{ACKNOWLEDGMENT}

Authors acknowledge the immense help received from the scholars whose articles are cited and included in references to this manuscript. The authors are also grateful to authors / editors / publishers of all those articles, journals, and books from which the literature for this article has been reviewed and discussed.

\section{Conflict of Interest: Nil}

\section{Source of Funding: Nil}

\section{REFERENCES}

1. Brenner E. Human body preservation-old and new techniques. J Anat 2014;224(3):316-44.

2. Bergman EM, Van Der Vleuten CP, Scherpbier AJ. Why don't they know enough about anatomy? A narrative review. Medical Teacher 2011;33(5):403-9.

3. Merriam-Webster's dictionary. Available at http://www.merriam-webster.com/

4. Brenner E.. Human Body Preservation- Old And New Techniques. J Anat 2014. 224(3): 1-6.

5. Hayat K, Qureshi AS, Rehan S, Rehman T. Plastination-An innovative preservative technique in anatomy. Trends Anat Physiol 2018;1(10)

6. Riederer BM. Plastination and its importance in teaching anatomy. Critical points for long-term preservation of human tissue. J Anat 2014 Mar;224(3):309-15.

7. Mahajan A, Agarwal S, Tiwari S, Vasudeva N. Plastination: An innovative method of preservation of dead body for teaching and learning anatomy. MAMC J Med Sci 2016;2(1):38.

8. Sora MC, Latorre R, Baptista C, López-Albors O. Plastination-A scientific method for teaching and research. Anatomia Histologia, Embryologia 2019;48(6):526-31.

9. Von Hagens G, inventor; Hagens Gunther Von, assignee. Animal and vegetal tissues permanently preserved by synthetic resin impregnation. United States patent US 4,205,059. 1980 May 27.

10. Henry RW. Silicone plastination of biological tissue: room-temperature technique North Carolina technique and products. J Int Soc Plastination 2007;22:26-30.

11. Henry RW. Principles of plastination-dehydration of specimens. J Int Soc Plastination 1995;9:27.

12. Henry RW, Nel PP. Forced impregnation for the standard S10 method. J Int Soc Plastination 1993;7(1):27-34.

13. Sivagnanam S, Ramesh G, Kannan TA, Kemphasi J. Epoxy resin plastination for lightweight poultry specimens. Asian J Sci Tech 2013;4(10):114-5. 